\title{
Shelter cats host infections with multiple Trypanosoma cruzi discrete typing units in southern Louisiana
}

\author{
Eric Dumonteil ${ }^{1,2^{*}}$ D, Hans Desale ${ }^{1,2}$, Weihong Tu ${ }^{1,2}$, Brandy Duhon ${ }^{3}$, Wendy Wolfson ${ }^{3}$, Gary Balsamo ${ }^{4}$ and \\ Claudia Herrera ${ }^{1,2}$
}

\begin{abstract}
Trypanosoma cruzi is a zoonotic parasite endemic in the southern US and the Americas, which may frequently infect dogs, but limited information is available about infections in cats. We surveyed a convenience sample of 284 shelter cats from Southern Louisiana to evaluate T. cruzi infection using serological and PCR tests. Parasites from PCR positive cats were also genotyped by PCR and deep sequencing to assess their genetic diversity. We detected a seropositivity rate for T. cruzi of at least $7.3 \%(17 / 234)$, and $24.6 \%$ of cats (70/284) were PCR positive for the parasite. Seropositivity increased with cat age $\left(R^{2}=0.91, P=0.011\right)$, corresponding to an incidence of $7.2 \% \pm 1.3$ per year, while $P C R$ positivity decreased with age $\left(R^{2}=0.93, P=0.007\right)$. Cats were predominantly infected with parasites from Tcl and TcVI DTUs, and to a lesser extent from TcIV and TCV DTUs, in agreement with the circulation of these parasite DTUs in local transmission cycles. These results indicate that veterinarians should have a greater awareness of T. cruzi infection in pets and that it would be important to better evaluate the risk for spillover infections in humans.
\end{abstract}

Keywords: Chagas disease, Genotyping, Discrete typing units, Phylogeny, Cat, Transmission cycle

\section{Introduction}

Trypanosoma cruzi is a zoonotic parasite that can cause Chagas disease in humans. The parasite can infect a wide diversity of mammalian species and transmission among these hosts occurs through contact with infected feces from hematophagous triatomine bugs. The disease affects at least 6 million people in the Americas [1], causing an estimated annual burden of $\$ 627.46$ million in health care costs [2].

In the US, the southern half of the country is endemic with well-established zoonotic cycles involving multiple species of triatomines [3] and multiple zoonotic, synantropic and domestic hosts, although the extent of

${ }^{*}$ Correspondence: edumonte@tulane.edu

${ }^{1}$ Department of Tropical Medicine, School of Public Health and Tropical Medicine, Tulane University, New Orleans, LA, USA

Full list of author information is available at the end of the article these cycles is only beginning to be understood [4]. T. cruzi infection in synantropic species such as opossums, rodents, or raccoons can be high [5-7], and these species may serve as a bridge between more sylvatic species and domestic hosts. Among the latter, dogs have been found to be a major host, as they serve as a frequent blood meal source for multiple triatomine species $[4,8-10]$ and have a $T$. cruzi infection rate up to $60 \%$ [11-16]. In Louisiana, $7-14 \%$ of shelter dogs are seropositive, and $14 \%$ are PCR positive for T. cruzi [16]. In multiple epidemiological settings, dogs are considered a risk factor for T. cruzi infection in humans [17-21].

Much less is known about T. cruzi infection in cats. A seroprevalence of infection of around 30\% has been reported in domestic cat populations in Mexico and Argentina [22-25]. In the US, a survey in southern Texas found $11.4 \%$ seropositive cats, but only $1.8 \%$ were PCR positive for T. cruzi [26]. Triatomine blood meal analyses

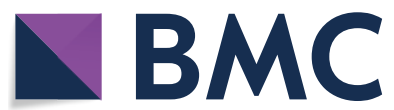

(c) The Author(s) 2021. This article is licensed under a Creative Commons Attribution 4.0 International License, which permits use, sharing, adaptation, distribution and reproduction in any medium or format, as long as you give appropriate credit to the original author(s) and the source, provide a link to the Creative Commons licence, and indicate if changes were made. The images or other third party material in this article are included in the article's Creative Commons licence, unless indicated otherwise in a credit line to the material. If material is not included in the article's Creative Commons licence and your intended use is not permitted by statutory regulation or exceeds the permitted use, you will need to obtain permission directly from the copyright holder. To view a copy of this licence, visit http://creativeco mmons.org/licenses/by/4.0/. The Creative Commons Public Domain Dedication waiver (http://creativecommons.org/publicdomain/ zero/1.0/) applies to the data made available in this article, unless otherwise stated in a credit line to the data. 
indicate that in Texas and Louisiana, $2-6 \%$ of blood meals are taken on cats $[4,8-10]$.

There is also an important genetic diversity of $T$. cruzi strains, and the parasite has been divided into seven main lineages or discrete typing units (DTUs) [27]. Recent studies in the southern US have highlighted a larger diversity of parasite DTU circulating in vectors and multiple hosts, including humans $[4,5,28-30]$. In particular shelter dogs were found to be infected with TcI, TcII, TcIV and TcV parasite DTUs [31]. As noted before, this parasite diversity can have important implications for the performance of diagnostic tests [32-34] as well as for the clinical development of the infection $[35,36]$.

Therefore, our objective was to evaluate T. cruzi infection in shelter cats from southern Louisiana, and assess parasite genetic diversity infecting these hosts, to better understand their contribution to the zoonotic circulation of the parasite in the region.

\section{Materials and methods Ethics statement}

The study received approval from Louisiana State University (Protocol \#19-099) and Tulane University (Protocol \#825) Institutional Animal Care and Use Committees (IACUC).

\section{Cat blood sample collection}

A convenience sample of 284 cat blood samples were collected during routine care and/or Spay-Neuter procedures from six animal shelters from southern Louisiana located in Calcasieu, East Baton Rouge, West Baton Rouge, Iberville, Lafourche and Orleans parishes. Blood samples were usually collected a few days after cat arrival at the shelters, and cat age was determined by expert veterinarians using a combination of teeth examination and body weight, unless age was available from owners. Whole blood was used to run InBios Stat-Pak rapid test, and serum was tested with a homemade ELISA for anti-T. cruzi IgG [16]. The antigen for the ELISA assay consisted of $10 \mu \mathrm{g} /$ well of $T$. cruzi parasite lysate from strain WB1, a TcI strain isolated from a local Triatoma sanguisuga bug [16]. An aliquot of blood was stored with $6 \mathrm{M}$ guanidine- $\mathrm{HCl}$, and processed for DNA extraction and T. cruzi PCR. Because of limited sample volume and variability in sample quality, all tests were performed in a subset of 222 samples, and only some of the tests were performed on the remaining 62 samples.

\section{T. cruzi PCR}

Blood samples were mixed with an equal amount of $6 \mathrm{M}$ guanidine- $\mathrm{HCl}$ overnight at room temperature $\left(20{ }^{\circ} \mathrm{C}\right)$, followed by total DNA extraction using Qiagen DNEasy Blood and Tissue Kit as per manufacturer's instructions
(Qiagen, Hilden, Germany). Total DNA concentration and quality were evaluated using a NanoDrop ${ }^{\mathrm{TM}}$ 2000/2000c Spectrophotometer (Thermo Fisher Scientific, Massachusetts, USA) and DNA was diluted to $2.5 \mathrm{ng} / \mu \mathrm{L}$ for use as a template in a standard Taq DNApolymerase PCR assay. Two primer sets were used in separate assays as previously described: primer sets TcZ1/TcZ2 [6, 37] and 121/122 [38] targeting a 188 bp T. cruzi nuclear repetitive microsatellite and 330 bp kinetoplast minicircle DNA sequence respectively. Presence of parasite amplicons was determined by agarose gel and ethidium bromide stain. DNA extraction, PCR setup, PCR reactions, and gel electrophoresis were completed in assigned cabinets located in specific areas of the laboratory to prevent cross contamination. Positive parasite and negative extraction and water controls were included alongside samples with each PCR run.

\section{Data analysis}

Seropositivity was considered confirmed when both the rapid test and the ELISA were reactive. However, because of important discordance between these tests [16], we also report the results of each test separately. We similarly report the rates of PCR positive cats for the kinetoplast and satellite nuclear DNA separately, as well as those positive for any one of the PCR targets. Agreement among tests was assessed by Kappa statistics. Proportions are presented with their $95 \%$ confidence interval $(95 \% \mathrm{CI})$. For the analysis of positivity rates with cat age, these were grouped into categories of $0-3$ months, 3.1-6 months, 6.1-12 months, 12.1-24 months, and $>24$ months of age. Non-linear regression was used to estimate incidence of exposure to T. cruzi.

\section{Genotyping and deep sequencing}

Parasite genotyping was performed on all T. cruzi PCR positive samples, using a multiplex PCR targeting the mini-exon sequence which gives PCR products of different sizes according to the DTU [39]. We also used TrypME3 and $\mathrm{TcCH}$ primers which amplify a larger fragment of $500 \mathrm{bp}$ of this marker from all DTUs [40]. Amplicons were pooled for each cat, processed for library preparation and sequenced on a MiSeq (Illumina) platform as before [31]. From 1000 to 500000 paired reads were obtained from each cat after quality filtering.

\section{Sequence analysis}

Raw Fastq reads were competitively mapped to miniexon reference sequences from each parasite DTU as previously described [41]. Reference sequences used were TcI: Raccoon70 (EF576837), TcII: Tu18 (AY367125), TcIII: M5631 (AY367126), TcIV: 92122102r (AY367124), TcV: SC43 (AY367127), TcVI: CL (U57984) and TcBat: 
TCC2477cl1 (KT305884). Sequence variants for each DTU were identified using FreeBayes SNP/variant tool [42] and only sequences representing at least $1 \%$ of the reads were conserved for analysis. Parasite mini-exon sequences from cats have been deposited in the GenBank database (Accession \#MW477900-MW477958). Phylogenetic trees based on maximum likelihood were built using PHYML as implemented in Geneious and mini-exon sequences from reference parasite strains from all DTUs were included for comparison: TcI: Raccoon70 (EF576837) and SilvioX10 (CP015667), TcII: Tu18 (AY367125) and AF1cl7 (FJ463161), TcIII: M5631 (AY367126) and M6241 (AF050522), TcIV: 92122102r (AY367124) and CanIII (AY367123), TcV: SC43 (AY367127) and MN (AY367128), TcVI: CL (U57984) and VSC (FJ463159) and TcBat: TCC2476cl6 (KT305883) and TCC1122cl7 (KT305876). Phylogenies were also constructed to compare parasite mini-exon sequences from cats with those from Triatoma sanguisuga vectors as well as other vertebrate hosts from southern Louisiana to assess their similarity $[4,28,29,31]$. A total of 100 bootstraps of the trees were performed to assess branch support.

\section{Results}

\section{T. cruzi infection in cats}

Based on a total of 284 cat blood samples, we were able to run two antibody tests (Stat-pak rapid test and ELISA) on 234 samples. A total of $17 / 234$ cats were confirmed seropositive for $T$. cruzi antibodies based on two reactive tests $(7.3 \%, 95 \%$ CI $[4.6,11.3])$. However, the agreement between the two tests was low $($ Kappa $=0.124)$, and 72/234 (30.8\%, 95\% CI [25.2, 37.0]) additional samples were reactive with a single serological test and considered serologically discordants (Table 1 ). Confirmed seropositivity was similar in female and male cats $(11 / 108$,
$10.2 \% 95 \%$ CI $[5.82,17.3]$ vs. $5 / 71,7.0 \%, 95 \%$ CI [3.1, 15.5], respectively, $P=0.23$ ).

Samples were then tested by PCR for T. cruzi DNA using primers targeting nuclear (TcZ1 and TcZ2 primers) and kinetoplast (121 and 122 primers) parasite DNA. A total of $41 / 284$ cats were positive with the nuclear DNA PCR $(14.4 \%, 95 \%$ CI $[10.8,19.0])$, and $52 / 284$ were positive with the kinetoplast DNA PCR $(18.3 \%, 95 \%$ CI [14.2, 23.2]). Agreement between the two PCR tests was fair $($ Kappa $=0.397)($ Table 2). Overall, based on a positive result in at least one PCR test, 70/284 cats were PCR positive for T. cruzi $(24.6 \%, 95 \%$ CI $[19.9,29.9])$.

Comparison of serology and PCR revealed important differences, as most seropositive cats were PCR negative, while most PCR positive cats were seronegative, resulting in a negligible agreement (Kappa $=-0.09)$ (Table 3). To further evaluate this, we analyzed how seropositivity and $P C R$ positivity varied with cat age. As expected, seropositivity increased with cat age $\left(R^{2}=0.91, P=0.011\right)$ (Figure 1), corresponding to an incidence of $7.2 \% \pm 1.3$ per year. Conversely, PCR positivity decreased with age $\left(R^{2}=0.93, P=0.007\right)$, suggesting that a high proportion of younger cats ( $<1$ year old) were infected with $T$. cruzi, but did not yet present high antibody levels, while a high proportion of older cats ( $>1$ year old) were seropositive but had very low levels of parasites.

\section{T. cruzi genotyping}

We then assessed T. cruzi genetic diversity based on the mini-exon marker. Samples from a total of 19 cats we successfully genotyped, 14 corresponding to cats with two positive PCR tests, five to cats having only a positive nuclear satellite DNA PCR, and none to cats having only a positive kinetoplast DNA PCR. A total of 60 Mini-exon sequences were obtained, corresponding to 3.2 haplotypes per cat, at frequencies of 1 to $100 \%$.
Table $1 T$. cruzi serological testing of cat samples

\begin{tabular}{llcr}
\hline & ELISA reactive & ELISA negative & \multicolumn{1}{l}{ Total } \\
\hline Rapid test reactive & $17(7.3 \%)$ & $31(13.2 \%)$ & $48(20.5 \%)$ \\
Rapid test negative & $41(17.5 \%)$ & $145(62.0 \%)$ & $186(79.5 \%)$ \\
Total & $58(24.8 \%)$ & $176(75.2 \%)$ & $234(100 \%)$ \\
\hline
\end{tabular}

Table 3 Comparison of T. cruzi PCR and serology testing

\begin{tabular}{lccc}
\hline & PCR positive & PCR negative & Total \\
\hline Seropositive & $2(0.9 \%)$ & $15(6.8 \%)$ & $17(7.7 \%)$ \\
Seronegative & $68(30.6 \%)$ & $137(61.7 \%)$ & $205(92.3 \%)$ \\
Total & $70(31.5 \%)$ & $152(68.5 \%)$ & $222(100 \%)$ \\
\hline
\end{tabular}

Table 2 T. cruzi PCR testing of cat samples

\begin{tabular}{llr}
\hline & Nuclear DNA positive & Nuclear DNA negative \\
\hline Kinetoplast DNA positive & $23(8.1 \%)$ & $29(10.2 \%)$ \\
Kinetoplast DNA negative & $18(6.3 \%)$ & $214(75.3 \%)$ \\
Total & $41(14.4 \%)$ & $243(85.6 \%)$ \\
\hline
\end{tabular}




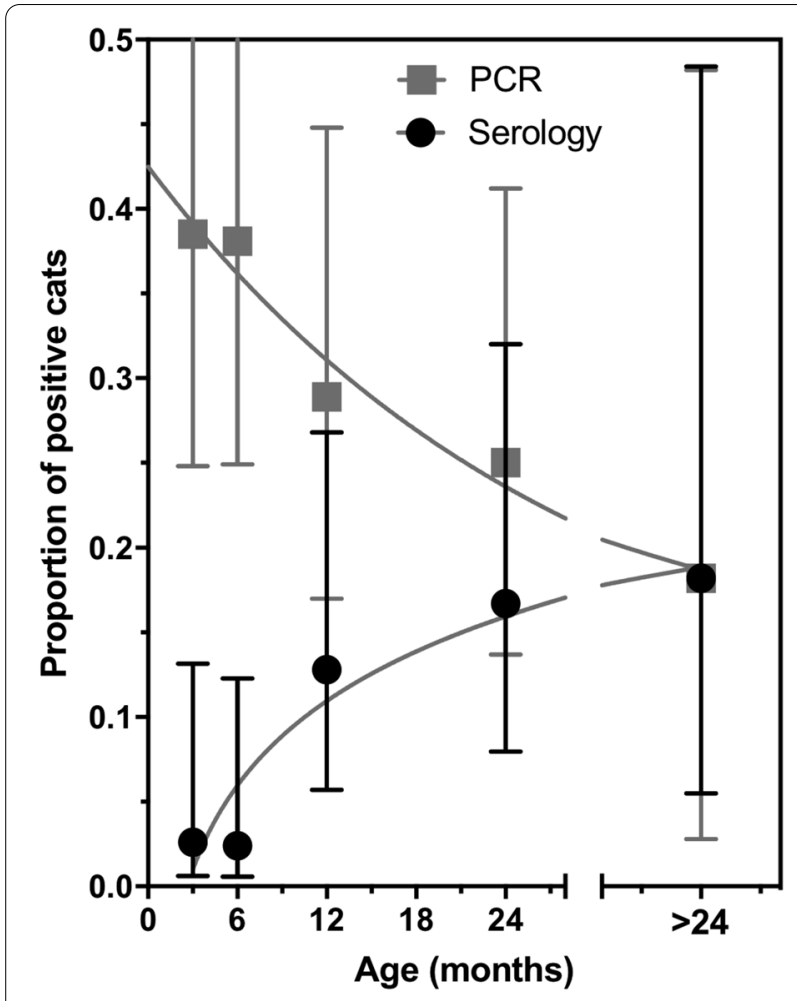

Figure 1 Seropositivity and PCR positivity according to cat age. Seropositivity significantly increased with cat age according to the following equation: Seropositivity $=-0.069+0.072 * \log ($ Age $)$, $P=0.011, R^{2}=0.91$. Conversely, $P C R$ positivity significantly decreased with cat age according to: $P C R$ positivity $=0.499-0.083 * \log ($ Age) , $P=0.007, R^{2}=0.93$.

Phylogenetic analysis indicated that cats were infected with T. cruzi parasites belonging to TcI, TcIV, TcV and TcVI DTUs (Figure 2), with most cats (16/19, 84\%) infected with multiple DTUs. Overall, TcI was the most frequent DTU, representing $57.1 \%$ of haplotypes, followed by TcVI (31.8\%), TcIV (8.3\%) and TcV (2.9\%). We then compared parasite haplotype sequences from cats with those of triatomine vectors and other mammalian host species from the region in more details, to assess their similarity. Parasite DTUs were analyzed separately for greater resolution of closely related sequences. TcI haplotypes from cats were identical or highly similar to haplotypes previously detected in Triatoma sanguisuga vectors as well as in mice, dogs and non-human primates from the region, and belonged to the TcIa subgroup (Figure 3A). On the other hand, TcId haplotypes found in dogs, mice and vectors were not detected in cats. Among TcII, TcV and TcVI DTUs, one cat harbored a $\mathrm{TcV}$ sequence related to those found in rodents, dogs and vectors, and many cats harbored sequences identical or closely related to TcVI sequences from mice and non-human primates (Figure 3B). No TcII sequences

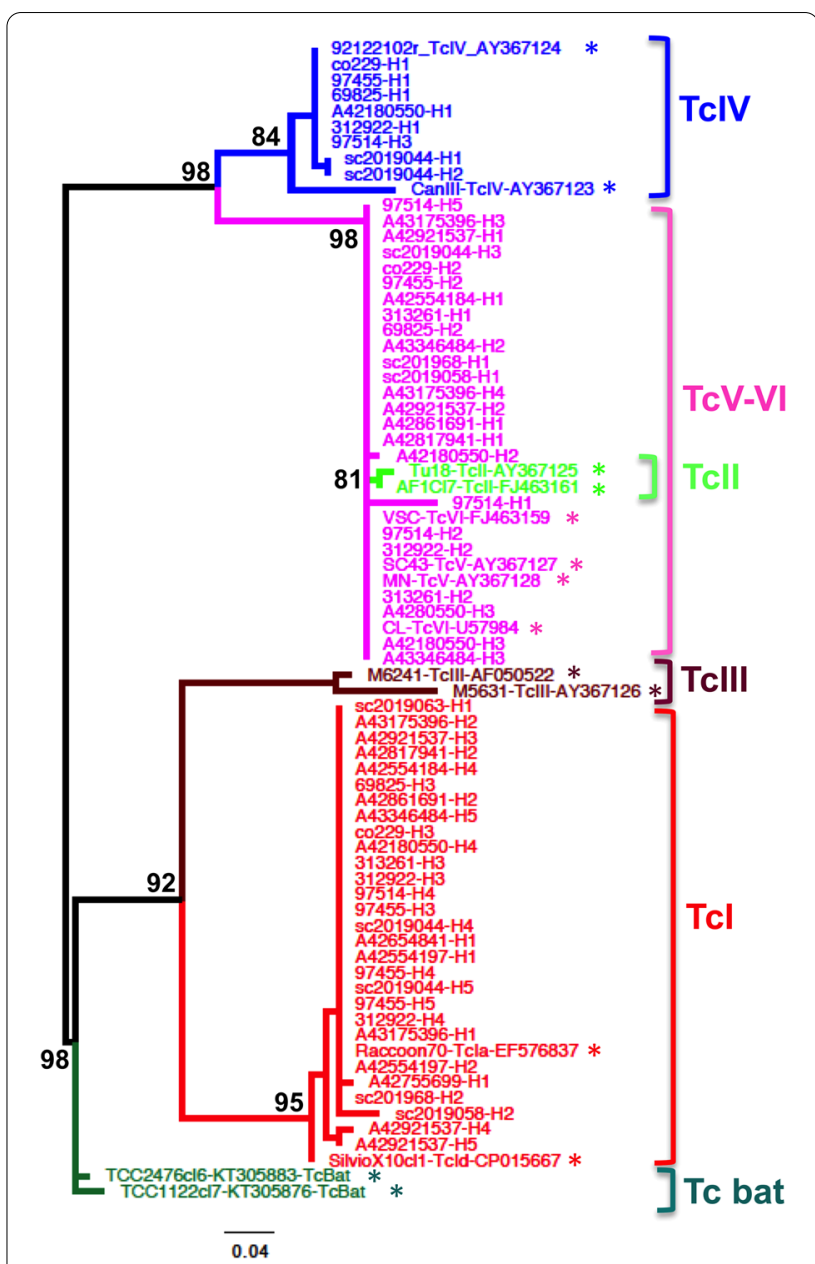

Figure 2 Phylogenetic analysis of $T$. cruzi sequences from cats. Maximum likelihood analysis of sequences from cats is shown, together with mini-exon sequences from reference T. cruzi strains from the indicated DTUs (TCl to TCVI and Tc bat). Bootstrap support is indicated only for the main nodes of the tree for clarity. Reference sequences are indicated with an asterisk.

were detected in cats, although these had been found in rodents, dogs and vectors. Finally, TcIV sequences from cats were similarly related to sequences from rats, dogs and vectors from southern Louisiana (Figure 3C). Together, these data confirmed the active circulation of these strains and DTUs among these hosts and vectors.

\section{Discussion}

Zoonotic transmission cycles of $T$. cruzi are well established in the southern US, making this region endemic for the parasite and suggesting a local risk for Chagas disease in humans [43]. Indeed, a growing number of autochthonous cases are being detected [44], but the domestic spillover of the parasite and the extent of risk for human infection remain difficult to estimate. Multiple 


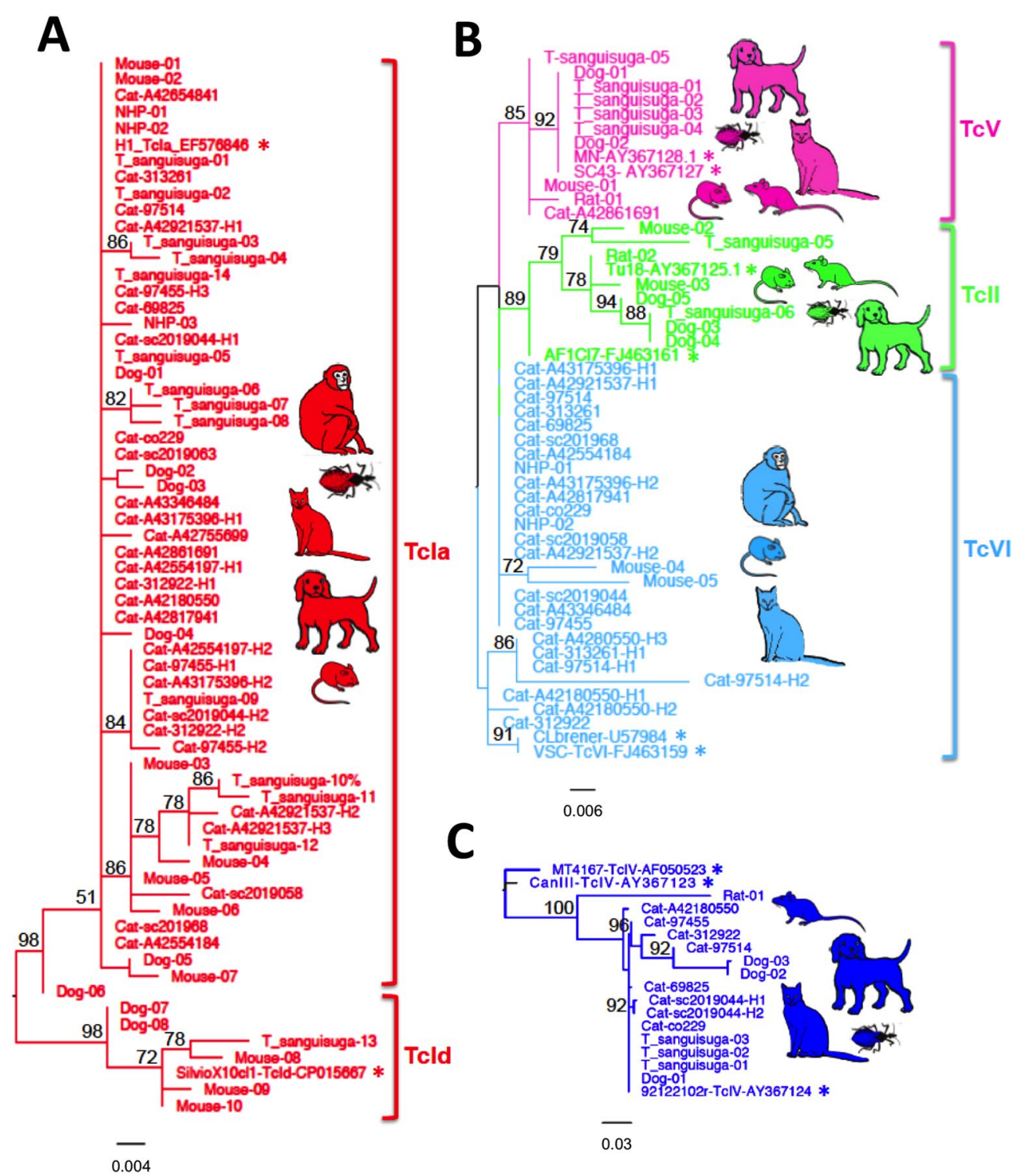

Figure 3 Comparison of parasite sequences from cats with other mammalian hosts and vectors from southern Louisiana. Maximum likelihood phylogenetic trees are shown for TCI (A), Tcll, TcV and TCVI (B) and TCIV DTUs (C). Only bootstrap node support > 50\% is indicated for clarity. Cartoons illustrate species harboring the respective parasite DTUs. Reference sequences are indicated with an asterisk.

studies have shown that a significant proportion of dogs, ranging from 1 to over $60 \%$, are infected with $T$. cruzi in the southern US [11-16]. We aimed here at evaluating $T$. cruzi infection in cats, for which data on T. cruzi infection is scarce.

Analysis of our cohort of shelter cats indicated a seropositivity rate for $T$. cruzi of $7.3 \%$, and $24.6 \%$ were PCR positive for the parasite. This is comparable to what was observed in shelter dogs from the region [16], although the rate of positive PCR seems somewhat higher in cats than in dogs. The seropositivity rate is also similar to that observed in cats from Texas (11.4\%), but we found a much higher proportion of PCR positive cats $(24.6 \%$ vs. $1.8 \%$ ) [26]. These data confirm the rather extensive circulation of the parasite in domestic animals in the southern US. Discrepancies among serological tests have been noted before, and may be due in part to differences in parasite strains/DTUs [16, 31, 45], as antigens used may not be sufficiently conserved [46].

While infection rates appear comparable between cats and dogs, analysis of triatomine blood meal source suggest that dogs are a much more frequent blood source 
than cats in the southern US [4, 8-10]. Analysis of incidence also indicates a much higher incidence in cats compared with dogs $(7.2 \%$ per year vs. $2.3 \%$ per year, respectively) [16]. These data suggest that differences in transmission dynamics (and potential mechanisms) may be occurring and cats may also become infected by the oral route through grooming or biting/eating bugs. Oral infections may also occur when feeding on rodents, which present T. cruzi infection rates of $11-76 \%$ in the region $[5,47]$. Further studies would be needed to clarify T. cruzi transmission mechanisms for cats and dogs.

We also observed important differences according to cat age. Younger cats were mostly PCR positive but seronegative for T. cruzi, suggesting that many may be in the acute phase of infection, and/or had not yet developed a strong antibody response against the parasite. On the other hand, older cats were mostly seropositive and few had detectable parasites in the blood, suggesting an effective immune control of the parasite. Little is know on the clinical progression of T. cruzi infection in cats, but histopathological analysis indicated some mild inflammation in multiple tissues from infected cats [26]. Further studies would be needed to assess the clinical impact of these infections, but veterinarians in the US should be more aware of T. cruzi infection in cats as well as in dogs.

The analysis of $T$. cruzi parasite genotypes confirmed that cats are involved in a regional transmission cycle with similar/identical T. cruzi strains as those circulating in other mammalian hosts, including rodents, dogs, non-human primates and T. sanguisuga vectors. This transmission cycle includes TcI, TcII, TcIV, TcV and TcVI parasite DTUs, although TcII was not detected in our cat cohort. This may be due to the limited sample size of successfully genotyped samples, although we cannot exclude that DTU frequencies may vary according to host (or vector) species. Cats have been found to be infected with TcI parasites in Texas $(N=3)$ [26]; and with TcVI in Argentina $(N=4)$ [48], which are two of the most frequent DTUs identified in our cohort. Shelter dogs in Louisiana were found to have somewhat different frequencies of $T$. cruzi DTUs, with TcI much more predominant, followed by TcIV, and lower frequencies for TcII, TcV and TcVI [31], which also seems to differ from DTU frequency in T. sanguisuga [4]. Parasite genotyping in autochthonous Chagas disease patients from Texas also revealed infections with TcI as well as non-TcI parasites [30], but no information is yet available on patients from Louisiana. Additional studies should help clarify if some host species have differential susceptibility to T. cruzi DTUs and may play different roles in sustaining parasite diversity. These genotyping results may also help improve serological diagnostics by providing information on the strains of T. cruzi parasites circulating in the region.
Our study has some limitations, as serological test discordance may result in underestimation of infections. The lack of information on clinical aspects and potential disease manifestations also indicates that further studies are needed to assess the clinical impact of T. cruzi infections in cats. Finally, although age estimates are reliable, some imprecisions may occur, particularly for older animals.

In conclusion, we identified a high T. cruzi infection rate in shelter cats from southern Louisiana, with a seropositivity rate of at least $7.2 \%$, and a PCR positive rate of $24.6 \%$. The data confirm that cats are an important domestic host for T. cruzi, which may have important implication for their veterinary care. On the other hand, the decreasing rates of positive PCR with cat age suggest that as they grow older, they may play a limited role in sustaining parasite domestic transmission. Analysis of parasite genotypes indicated that cats predominantly harbor parasites from TcI and TcVI DTUs, and to a lesser extent from TcIV and TcV DTUs. This confirmed the circulation of these parasite DTUs in local transmission cycles and the high diversity of parasite DTUs in the southern US. These results indicate that it would be important to better evaluate the risk for spillover infections in humans.

\section{Acknowledgements \\ We thank all shelter veterinarians who helped with blood sample collection. \\ Authors' contributions \\ $\mathrm{ED}, \mathrm{CH}, \mathrm{WW}$ designed the study; $H D, W T, B D, W W$ performed the experi- ments; $\mathrm{ED}, \mathrm{CH}, \mathrm{GB}$ analyzed the data; $\mathrm{ED}$ drafted the manuscript; all authors provided revisions to the manuscript. All authors read and approved the final manuscript. \\ Funding \\ This project was supported by grant \#W19-002 from the Winn Feline Founda- tion. The contents of this publication are solely the responsibility of the authors and no not necessarily represent the views of Winn. Support was also provided by the Louisiana Board of Regents through the Board of Regents Support Fund [\# LESASF (2018-21)-RD-A-19] to ED.}

\section{Declarations}

\section{Ethics approval and consent to participate}

The study received approval from Louisiana State University and Tulane University Institutional Animal Care and Use Committees (IACUC).

\section{Competing interests}

The authors declare that they have no competing interests.

\section{Author details}

${ }^{1}$ Department of Tropical Medicine, School of Public Health and Tropical Medicine, Tulane University, New Orleans, LA, USA. ${ }^{2}$ Vector-Borne and Infectious Disease Research Center, Tulane University, New Orleans, LA, USA. ${ }^{3}$ School of Veterinary Medicine, Louisiana State University, Baton Rouge, LA, USA.

${ }^{4}$ Infectious Disease Epidemiology Section, Office of Public Health, Department of Health, New Orleans, LA, USA.

Received: 25 January 2021 Accepted: 12 March 2021

Published online: 06 April 2021 


\section{References}

1. WHO (2015) Chagas disease in Latin America: an epidemiological update based on 2010 estimates. Wkly Epidemiol Rec 90:33-43

2. Lee BY, Bacon KM, Bottazzi ME, Hotez PJ (2013) Global economic burden of Chagas disease: a computational simulation model. Lancet Infect Dis 13:342-348. https://doi.org/10.1016/S1473-3099(13)70002-1

3. Curtis-Robles R, Hamer SA, Lane S, Levy MZ, Hamer GL (2018) Bionomics and spatial distribution of triatomine vectors of Trypanosoma cruzi in Texas and other southern states, USA. Am J Trop Med Hyg 98:113-121. https://doi.org/10.4269/ajtmh.17-0526

4. Dumonteil E, Pronovost H, Bierman EF, Sanford A, Majeau A, Moore R, Herrera C (2020) Interactions among Triatoma sanguisuga blood feeding sources, gut microbiota and Trypanosoma cruzi diversity in southern Louisiana. Mol Ecol 29:3747-3761

5. Herrera CP, Licon MH, Nation CS, Jameson SB, Wesson DM (2015) Genotype diversity of Trypanosoma cruzi in small rodents and Triatoma sanguisuga from a rural area in New Orleans, Louisiana. Parasites Vectors 8:123. https://doi.org/10.1186/s13071-015-0730-8

6. Majeau A, Pronovost H, Sanford A, Cloherty E, Anderson AN, Balsamo G, Gee L, Straif-Bourgeois SC, Herrera C (2020) Raccoons as an important reservoir for Trypanosoma cruzi: a prevalence study from two metropolitan areas in Louisiana. Vector Borne Zoonotic Dis 20:535-540. https://doi. org/10.1089/vbz.2019.2559

7. Zecca IB, Hodo CL, Slack S, Auckland L, Hamer SA (2020) Trypanosoma cruzi infections and associated pathology in urban-dwelling Virginia opossums (Didelphis virginiana). Int J Parasitol Parasites Wildl 11:287-293. https://doi.org/10.1016/j.ijppaw.2020.03.004

8. Kjos SA, Marcet PL, Yabsley MJ, Kitron U, Snowden KF, Logan KS, Barnes JC, Dotson EM (2013) Identification of bloodmeal sources and Trypanosoma cruzi infection in triatomine bugs (Hemiptera: Reduviidae) from residential settings in Texas, the United States. J Med Entomol 50:1126-1139. https://doi.org/10.1603/ME12242

9. Waleckx E, Suarez J, Richards B, Dorn PL (2014) Triatoma sanguisuga blood meals and potential for Chagas disease, Louisiana, USA. Emerg Infect Dis 20:2141-2143. https://doi.org/10.3201/eid2012.131576

10. Gorchakov R, Trosclair LP, Wozniak EJ, Feria PT, Garcia MN, Gunter SM, Murray KO (2016) Trypanosoma cruzi infection prevalence and bloodmeal analysis in triatomine vectors of Chagas disease from rural peridomestic locations in Texas, 2013-2014. J Med Entomol 53:911-918. https://doi. org/10.1093/jme/tjw040

11. Nieto PD, Boughton R, Dorn PL, Steurer F, Raychaudhuri S, Esfandiari J, Goncalves E, Diaz J, Malone JB (2009) Comparison of two immunochromatographic assays and the indirect immunofluorescence antibody test for diagnosis of Trypanosoma cruzi infection in dogs in south central Louisiana. Vet Parasitol 165:241-247. https://doi.org/10.1016/j.vetpar. 2009.07.010

12. Vakalis N, Miller JH, Lauritsen E, Hansen D (1983) Anti-Trypanosoma cruzi antibodies among domestic dogs in New Orleans. J Louisiana State Med Soc 135:14-15

13. Williams GD, Adams LG, Yaeger RG, McGrath RK, Read WK, Bilderback WR (1977) Naturally occurring trypanosomiasis (Chagas' disease) in dogs. J Am Vet Med Assoc 171:171-177

14. Kjos SA, Snowden KF, Craig TM, Lewis B, Ronald N, Olson JK (2008) Distribution and characterization of canine Chagas disease in Texas. Vet Parasitol 152:249-256

15. Tenney TD, Curtis-Robles R, Snowden KF, Hamer SA (2014) Shelter dogs as sentinels for Trypanosoma cruzi transmission across Texas. Emerg Infect Dis 20:1323-1326. https://doi.org/10.3201/eid2008.131843

16. Elmayan A, Tu W, Duhon B, Marx P, Wolfson W, Balsamo G, Herrera C, Dumonteil E (2019) High prevalence of Trypanosoma cruzi infection in shelter dogs from southern Louisiana, USA. Parasites Vectors 12:322. https://doi.org/10.1186/s13071-019-3572-y

17. Crisante G, Rojas A, Teixeira MM, Anez N (2006) Infected dogs as a risk factor in the transmission of human Trypanosoma cruzi infection in western Venezuela. Acta Trop 98:247-254

18. Castanera MB, Lauricella MA, Chuit R, Gurtler RE (1998) Evaluation of dogs as sentinels of the transmission of Trypanosoma cruzi in a rural area of north-western Argentina. Ann Trop Med Parasitol 92:671-683

19. Cohen JE, Gürtler RE (2001) Modeling household transmission of american trypanosomiasis. Science 293:694-698
20. Flores-Ferrer A, Waleckx E, Rascalou G, Dumonteil E, Gourbière S (2019) Trypanosoma cruzi transmission dynamics in a synanthropic and domesticated host community. PLoS Negl Trop Dis 13:e0007902. https://doi.org/ 10.1371/journal.pntd.0007902

21. Gurtler RE, Cardinal MV (2015) Reservoir host competence and the role of domestic and commensal hosts in the transmission of Trypanosoma cruzi. Acta Trop 151:32-50. https://doi.org/10.1016/j.actatropica.2015.05.029

22. Gurtler RE, Cecere MC, Lauricella MA, Cardinal MV, Kitron U, Cohen JE (2007) Domestic dogs and cats as sources of Trypanosoma cruzi infection in rural northwestern Argentina. Parasitology 134:69-82

23. Enriquez GF, Cardinal MV, Orozco MM, Schijman AG, Gurtler RE (2013) Detection of Trypanosoma cruzi infection in naturally infected dogs and cats using serological, parasitological and molecular methods. Acta Trop 126:211-217. https://doi.org/10.1016/j.actatropica.2013.03.001

24. Enriquez GF, Bua J, Orozco MM, Wirth S, Schijman AG, Gurtler RE, Cardinal MV (2014) High levels of Trypanosoma cruzi DNA determined by qPCR and infectiousness to Triatoma infestans support dogs and cats are major sources of parasites for domestic transmission. Infect Genet Evol 25:36-43. https://doi.org/10.1016/j.meegid.2014.04.002

25. Jimenez-Coello M, Acosta-Viana KY, Guzman-Marin E, Gomez-Rios A, Ortega-Pacheco A (2012) Epidemiological survey of Trypanosoma cruzi infection in domestic owned cats from the tropical southeast of Mexico. Zoonoses Public Health 59:102-109. https://doi.org/10.1111/j.1863-2378. 2012.01463.x

26. Zecca IB, Hodo CL, Slack S, Auckland L, Rodgers S, Killets KC, Saunders AB, Hamer SA (2020) Prevalence of Trypanosoma cruzi infection and associated histologic findings in domestic cats (Felis catus). Vet Parasitol 278:109014. https://doi.org/10.1016/j.vetpar.2019.109014

27. Zingales B (2017) Trypanosoma cruzi genetic diversity: something new for something known about Chagas disease manifestations, serodiagnosis and drug sensitivity. Acta Trop 184:38-52. https://doi.org/10.1016/j.actat ropica.2017.09.017

28. Herrera C, Majeau A, Didier P, Falkenstein KP, Dumonteil E (2019) Trypanosoma cruzi diversity in naturally infected non-human primates in Louisiana assessed by deep sequencing of the mini-exon gene. Trans $R$ Soc Trop Med Hyg 113:281-286. https://doi.org/10.1093/trstmh/try119

29. Pronovost H, Peterson AC, Ghersi Chavez B, Blum MJ, Dumonteil E, Herrera $C$ (2020) Deep sequencing reveals multiclonality and new discrete typing units of Trypanosoma cruzi in rodents from the southern United States. J Microbiol Immunol Infect 53:622-633. https://doi.org/10.1016/j. jmii.2018.12.004

30. Garcia MN, Burroughs H, Gorchakov R, Gunter SM, Dumonteil E, Murray KO, Herrera CP (2017) Molecular identification and genotyping of Trypanosoma cruzi DNA in autochthonous Chagas disease patients from Texas, USA. Infect Genet Evol 49:151-156. https://doi.org/10.1016/j.meegid. 2017.01.016

31. Dumonteil E, Elmayan A, Majeau A, Tu W, Duhon B, Marx P, Wolfson W, Balsamo G, Herrera C (2020) Genetic diversity of Trypanosoma cruzi parasites infecting dogs in southern Louisiana sheds light on parasite transmission cycles and serological diagnostic performance. PLoS Negl Trop Dis 14:e0008932

32. Guzman-Gomez D, Lopez-Monteon A, de la Soledad L-C, AlvarezMartinez C, Hernandez-Lutzon MJ, Dumonteil E, Ramos-Ligonio R (2015) Highly discordant serology against Trypanosoma cruzi in central Veracruz, Mexico: role of the antigen used for diagnostic. Parasites Vectors 8:466. https://doi.org/10.1186/s13071-015-1072-2

33. Cooley G, Etheridge RD, Boehlke C, Bundy B, Weatherly DB, Minning T, Haney M, Postan M, Laucella S, Tarleton RL (2008) High throughput selection of effective serodiagnostics for Trypanosoma cruzi infection. PLoS Negl Trop Dis 2:e316. https://doi.org/10.1371/journal.pntd.0000316

34. Afonso AM, Ebell MH, Tarleton RL (2012) A systematic review of high quality diagnostic tests for Chagas disease. PLoS Negl Trop Dis 6:e1881. https://doi.org/10.1371/journal.pntd.0001881

35. Whitman JD, Bulman CA, Gunderson EL, Irish AM, Townsend RL, Stramer SL, Sakanari JA, Bern C (2019) Chagas disease serological test performance in U.S. blood donor specimens. J Clin Microbiol 57:e01217-e1219. https://doi.org/10.1128/JCM.01217-19

36. Dumonteil E, Herrera C (2017) Ten years of Chagas disease research: looking back to achievements, looking ahead to challenges. PLoS Negl Trop Dis 11:e0005422. https://doi.org/10.1371/journal.pntd.0005422 
37. Moser DR, Kirchhoff LV, Donelson JE (1989) Detection of Trypanosoma cruzi by DNA amplification using the polymerase chain reaction. J Clin Microbiol 27:1477-1482

38. Sturm NR, Degrave W, Morel C, Simpson L (1989) Sensitive detection and schizodeme classification of Trypanosoma cruzi cells by amplification of kinetoplast minicircle DNA sequences: use in diagnosis of Chagas' disease. Mol Biochem Parasitol 33:205-214

39. Souto RP, Fernandes O, Macedo AM, Campbell DA, Zingales B (1996) DNA markers define two major phylogenetic lineages of Trypanosoma cruzi. Mol Biochem Parasitol 83:141-152. https://doi.org/10.1016/S01666851(96)02755-7

40. Majeau A, Herrera C, Dumonteil E (2019) An improved approach to Trypanosoma cruzi molecular genotyping by next-generation sequencing of the mini-exon gene. Methods Mol Biol 1955:47-60

41. Villanueva-Lizama L, Teh-Poot C, Majeau A, Herrera C, Dumonteil E (2019) Molecular genotyping of Trypanosoma cruzi by next-generation sequencing of the mini-exon gene reveals infections with multiple parasite discrete typing units in chagasic patients from Yucatan, Mexico. J Infect Dis 219:1980-1988. https://doi.org/10.1093/infdis/jiz047

42. Garrison E, Marth G (2012) Haplotype-based variant detection from short-read sequencing. arXiv preprint, pp 1-9

43. Bern C, Messenger LA, Whitman JD, Maguire JH (2019) Chagas disease in the United States: a public health approach. Clin Microbiol Rev 33:e00023-e119. https://doi.org/10.1128/CMR.00023-19
44. Lynn MK, Bossak BH, Sandifer PA, Watson A, Nolan MS (2020) Contemporary autochthonous human Chagas disease in the USA. Acta Trop 205:105361. https://doi.org/10.1016/j.actatropica.2020.105361

45. Meyers AC, Meinders M, Hamer SA (2017) Widespread Trypanosoma cruzi infection in government working dogs along the Texas-Mexico border: discordant serology, parasite genotyping and associated vectors. PLoS Negl Trop Dis 11:e0005819. https://doi.org/10.1371/journal.pntd.0005819

46. Majeau A, Murphy L, Herrera C, Dumonteil E (2021) Assessing Trypanosoma cruzi parasite diversity through comparative genomics: implications for disease epidemiology and diagnostics. Pathogens 10:212. https://doi. org/10.3390/pathogens 10020212

47. Ghersi BM, Peterson AC, Gibson NL, Dash A, Elmayan A, Schwartzenburg H, Tu W, Riegel C, Herrera C, Blum MJ (2020) In the heart of the city: Trypanosoma cruzi infection prevalence in rodents across New Orleans. Parasites Vectors 13:577. https://doi.org/10.1186/s13071-020-04446-y

48. Cardinal MV, Lauricella MA, Ceballos LA, Lanati L, Marcet PL, Levin MJ, Kitron U, Gurtler RE, Schijman AG (2008) Molecular epidemiology of domestic and sylvatic Trypanosoma cruzi infection in rural northwestern Argentina. Int J Parasitol 38:1533-1543

\section{Publisher's Note}

Springer Nature remains neutral with regard to jurisdictional claims in published maps and institutional affiliations.
Ready to submit your research? Choose BMC and benefit from:

- fast, convenient online submission

- thorough peer review by experienced researchers in your field

- rapid publication on acceptance

- support for research data, including large and complex data types

- gold Open Access which fosters wider collaboration and increased citations

- maximum visibility for your research: over $100 \mathrm{M}$ website views per year

At BMC, research is always in progress.

Learn more biomedcentral.com/submissions 